\title{
RESPEITAR O OUTRO ${ }^{1}$
}

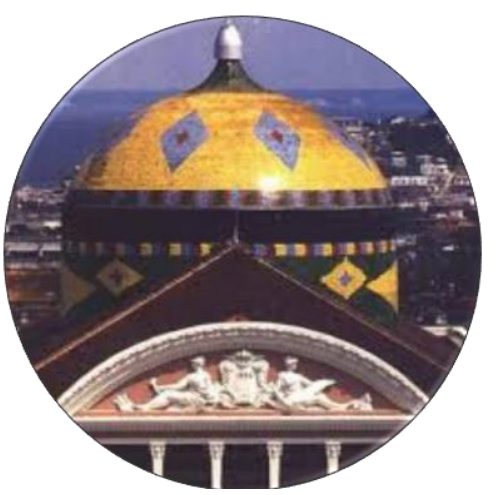

Michel Justamand

\begin{abstract}
Resumo
O presente texto discorre sobre a diversidade sociocultural na região do Alto Solimões por meio de relações com outros locais e tempos, bem como por comentários a propósito do que conhecemos na região na qual se localiza o Instituto de Natureza e Cultura (INC) da Universidade Federal do Amazonas (UFAM). Esta produção terá um enfoque geral sobre culturas, crenças, guerras rituais, doenças, curas e modos de vida na Amazônia, ressaltando que é preciso entender e respeitar os saberes do outro e seus conhecimentos, muitas vezes, diversos dos nossos.
\end{abstract}

Palavras-chave: Outro. Respeito. Alto Solimões

\begin{abstract}
The present text deals with socio-cultural diversity in the Alto Solimões region through relations with other places and times, as well as comments about what we know in the region where the Institute of Nature and Culture (INC) of the Federal University of Amazonas (UFAM). This production will have a general focus on cultures, beliefs, ritual wars, diseases, cures and ways of life in Amazonia, emphasizing that it is necessary to understand and respect the knowledge of the other and their knowledge, often different from ours.
\end{abstract}

Keywords: Other. Respect. Alto Solimões

${ }^{1}$ Este texto origina-se de uma conferência realizada no Projeto de Extensão Amazônia e Meio Ambiente: Conhecimentos, Saberes Tradicionais e Direitos a Diversidade, vinculado à Pró-Reitoria de Extensão e Interiorização - PROEXTI, voltado para discentes do Instituto de Natureza e Cultura (INC) da Universidade Federal do Amazonas, na cidade de Benjamin Constant, no Alto Solimões, e coordenado por Cláudia dos Santos Lima. 
Assim, vejamos...

\section{Conversando com o outro}

Gersem Luciano Baniwa pontua que, quando se trata da aceitação da diversidade cultural e étnica, é sempre muito fácil falar - e muitos discursam e escrevem sobre ela - mas colocá-la em prática e realizá-la é deveras algo muito diverso e difícil. Para o referido autor, aceitar e respeitar a diversidade cultural são desafios (BANIWA, 2008, p. 65). Mas salienta que, de qualquer forma, é preciso encarar esse desafio para que todas e todos tenham espaço, voz e vez.

Tomando a região do Alto Solimões/AM como mote onde existe uma rica diversidade cultural, linguística, religiosa, devemos aprender a construir formas de relacionamento que incorporem as práticas sociais e os saberes dos outros, dos diferentes. Estes possuem conhecimentos socioambientais locais e outros modos de vida originais, que podem ser utilizados se conhecidos por todos dali e do mundo, podendo deixar de usar aqueles modelos de vida impostos pelo sistema dominante (JUSTAMAND, 2010).

A diversidade cultural na região do Alto Solimões está diretamente relacionada com suas relações e questões fronteiriças, dado que ali o Brasil faz fronteira tríplice. Neste ambiente, há uma diversidade de ações entre esses países, apenas para citar algumas: questões urbanas com o Peru (MARTINS et alii, 2015); questões étnicas com a Colômbia (TOBÓN, 2015); e questões religiosas entre esses países e o Brasil (SAENS, 2012). Tais fatores proporcionam ali modos diversos de ver a vida.

Essa região possui posicionamentos socioculturais interessantes que, se forem divulgados, podem ser úteis tanto para todas e todos dali como para indivíduos de outras partes, haja vista serem portadores de ensinamentos locais interessantes, desde há milhares de anos, formulados 
pelos ocupantes da Amazônia (ADEDATO, 2006, p. 30). Conhecimentos estes que foram mantidos informalmente, fontes empregadas para lidar com o meio ambiente, animais e plantas, e com as relações interpessoais, em sua maioria indígena; atualmente, são sabedorias divididas e impregnadas na vida de todos os que ali vivem, mas são saberes que devem contribuir para a vida de outros (KERR, 2005, p. 65).

No Alto Solimões, notamos esses valores no modo de agir, pensar e viver, como nas práticas rituais dos xamãs, como a Ayahuasca (BIANCHI, 2005) ou a de mambear coca amazônica (ECHEVERRI; PEREIRA, 2005). Salientamos que é importante conhecer essas formas sociais de agir a fim de ampliar a compreensão total do outro; usamos aqui a definição desenvolvida por Carlos Moore em seus escritos sobre as relações de racismo em nossas sociedades (MOORE, 2007).

Tharcisio Santiago Cruz indica que no Alto Solimões existiria um equilíbrio interessante na relação dos humanos com o meio ambiente; enfatiza elementos que concerne ao uso de recursos naturais, especialmente, pesqueiros e florestais (CRUZ, 2012, p. 101); tais exemplos poderiam ser úteis para outros locais, ou seja, utilizar-se do que essa região pode oferecer.

Nossa Carta Magna de 1988 apregoa que todos têm o direito a sua identidade cultural, por mais diversa que esta seja. Essa é, como pensamos, a Constituição mais próxima dos interesses de salvaguarda dos diferentes, dos grupos menosprezados, esquecidos; este dispositivo legal se preocupou em proteger legalmente os diferentes. Então, é preciso que tentemos, ao menos, colocá-lo em prática, dado que muitas vezes em nosso país as leis não pegam. De fato, algo muito estranho, mas é assim: a lei é criada e oficializada, na Constituição, por exemplo. Contudo, muitos não querem o seu funcionamento por se sentirem prejudicado, aí buscam inviabilizar algo. Parece-nos que é preciso exigir permanentemente nossos direitos explícitos na maior carta do país, a Constituição Federal. Ela deve ser lida, relida e 
estudada. É preciso reivindicar que os direitos ali expressos sejam concretizados em políticas públicas para todas e todos.

Faz-se mister também reconhecer o valor e o respeito às práticas tradicionais locais. Julgamos serem importantes esses valores para a região e também para outros locais. Gilse Elisa Rodrigues identifica essa vontade de expandir os valores em relação a representantes femininas de muitas etnias do Vale do Javari, no Alto Solimões. A autora mostra que as mulheres tinham como demanda local a criação de uma associação feminina indígena; essa construção da associação tinha como objetivo implícito a visibilidade dessas mulheres nas sociedades indígenas em que vivem, mas não só, podendo ser também entre outras sociedades da região e, quem sabe, do Brasil (RODRIGUES, 2012, p. 51).

\section{Respeitar o outro e sua ancestralidade}

Parece-nos ser preciso respeitar saberes transmitidos social ou historicamente entre os grupos. Saberes estes concebidos e forjados ao longo de milhares de anos e mantidos pela transmissão oral, sendo ampliados e usados por todos os grupos e habitantes da região onde surgiram. Deste modo, foram conservados em benefício de todos nós. Lembrando-nos de Bráz França Baré, que descreve que entre os indígenas da etnia baré, os saberes são divididos; essa metodologia social é útil para que seja garantida a boa relação entre os grupos (BARÉ, 2015, p. 37). Assim, cria-se a codependência no âmbito dos grupos e todos precisam respeitar o fazer e conhecimento do outro, o que deve ter acontecido no Alto Solimões, bem como em outras partes amazônicas, onde os saberes e conhecimentos são divididos e utilizados por todos.

Para Luis Eduardo Luna, diversos conhecimentos da região amazônica baseiam-se na experiência dos povos que ali vivem ou viveram; tais conhecimentos estão ligados especialmente ao mundo indígena, como é 
o caso da Ayahuasca. E esses saberes acoplados se ligam a outros tantos dos povos amazônicos, transformando-se em contribuições efetivas, por exemplo, para a farmacologia da consciência (LUNA, 2005, p. 334 e 339). $\mathrm{O}$ autor menciona que nos locais onde os rituais ligados à prática da Ayahuasca foram mantidos, os grupos indígenas têm resistido aos embates que pretendiam realizar sua desintegração sociocultural (LUNA, 2005, p. 340). Reafirmamos aqui: respeitar o outro e seus saberes, é preciso!

Já João Paulo Lima Barreto mostra que os grupos indígenas conhecem bem como lidar com os peixes. Acrescenta que eles têm ciência sobre o momento ideal de pescar e qual espécie comer, evitando lidar com problemas posteriores, como a falta desse alimento - pois não devem abusar comendo-os fora de seu devido período (BARRETO, 2013). É saber dos indígenas, mas também de outros grupos tradicionais, o modo como usar sementes, plantas, frutos e árvores para determinado fim. Podendo ser o de produção artística cultural, alimentar, medicinal, dentre outros. Esses grupos têm conhecimento sobre qual ou quais são as ervas para cura, as que curam e quais seus respectivos procedimentos (LIMA, 2012).

Saber é poder e tem preço.

Infelizmente, como é de conhecimento de muitos, tudo tem um preço no sistema capitalista mundial atual. Inclusive os saberes tradicionais indígenas e de outros grupos, tais como caboclos, caiçaras, ciganos, ribeirinhos, quilombolas. No entanto, poucas vezes esses grupos recebem retornos de seus conhecimentos oferecidos ao mundo. Não se sabe ao certo nem o valor que as empresas conseguem com os conhecimentos repassados por esses grupos. Não temos essa dimensão e nem é oferecida para a população de maneira geral tais informações sobre a indústria farmacêutica ou outras. De toda forma, é preciso que sejam realizados os devidos repasses aos principais detentores. É necessário que ocorra alguma devolutiva econômica para os possuidores de tais saberes, tendo em vista 
que muitos se aproveitam e ainda fazem fortuna com esses conhecimentos; tal situação que ocorre dentro e fora do país.

Gersem Baniwa assevera que há, em solo brasileiro, mais de 220 povos indígenas - mesmo depois de todos os ataques, em forma de guerra, doenças ou maus-tratos - com suas formas de agir, ver e pensar o mundo. Eles têm suas línguas, tradições e saberes que enriquecem a todos (BANIWA, 2008, p. 67). Enriquecimento este que vale para todos os indivíduos, tanto no presente momento quanto no futuro.

Caso ocorra a destruição completa dos conhecimentos tradicionais e dos saberes - conforme parece que vem ocorrendo -, serão perdidas informações inestimáveis para a vida de todas e todos e úteis para outros locais. Todos seremos cúmplices desse ato, por esses povos não terem sido respeitados, entendidos, e não terem sido observados seus devidos valores para a vida humana e outras. Em muitos casos, simplesmente por puro preconceito cultural dos vencedores, alguns que venceram pela força das armas, outros das doenças, e/ou pelo "povo da mercadoria" - definição utilizada por David Kopenawa e Bruce Albert, em A queda do céu. Palavras de uma xamã yanomami (KOPENAWA; ALBERT, 2015, p. 27) a fim de descrever a intervenção dos brancos.

No Brasil, ainda se trata oficialmente da chegada dos europeus como sendo uma descoberta, infelizmente, de outro mundo. Mas nesse outro mundo, muitas histórias já estavam em processo. Assim, entendemos que muito antes do ano de 1500 há parte da história ancestral de milhares de pessoas que já habitavam a América, muitas delas, no Brasil. Tais habitantes deixaram marcas por todos os locais onde passaram, como por exemplo, as artes rupestres. Este tipo de vestígio arqueológico está espalhado por todos os estados do país; nelas, podemos observar os registros da vida dos primeiros habitantes, com aventuras e desventuras pelas matas brasileiras. Essas artes foram feitas, em alguns casos, há mais de 10 mil de anos. As inscrições rupestres compõem um cabedal com 
inúmeras cenas do cotidiano ancestral: ali se notam caçadas, rituais, sexo, danças, lutas e movimentações/ações daqueles grupos produtores (JUSTAMAND, 2015). Tais vestígios mostram que os humanos que por aqui viveram fizeram sua própria história e tiveram suas relações sociais, importantes para a manutenção da vida humana. Os grupos certamente realizavam trocas e intercâmbios culturais, como podemos notar nas diversas temáticas das cenas rupestres.

As cenas pintadas nas rochas representam momentos das vidas de antepassados que foram registrados para usos no futuro, seja por parentes ou outros usuários/grupos daquelas informações - tal como devem ser os saberes tradicionais, conquistados e desenvolvidos ao longo de muitas gerações, garantidos, conservados e disseminados, de modo a serem lembrados, valorizados e usados por infinitos grupos.

Infelizmente, parece-nos, que em nosso país esses saberes e informações preservados há milhares de anos ainda sejam pouco conhecidos e reconhecidos. Parece-nos que todo o conhecimento tradicional, seja indígena, ribeirinho, quilombola e/ou caboclo, é tratado como inferior ou é menosprezado em terras brasileiras.

Os conhecimentos tradicionais, especialmente, indígenas, fogem aos padrões sistêmicos de como devem ser enquadrados, medidos, expostos, vividos e ou experimentados; talvez seja esse o motivo, o desprezo e/ou a tentativa de emudecê-los. Esses saberes são usados de modos diversos entre os grupos, mas podem ser úteis para todas e todos, em qualquer parte do mundo.

$O$ fato de esses saberes não serem abarcados nas medidas da ciência, muitas vezes, faz com que eles se tornem diversos daqueles que conhecemos e se transformem em conhecimentos que não se incorporem às "estantes" e laboratórios da ciência formal. Deste modo, somente são vistos e estudados quando do interesse e dos lucros de grandes corporações nacionais e/ou multinacionais. 
A sociedade internacional cria padrões de vida, estéticos, sociais, culturais e morais. Esses padrões são concebido a fim de facilitar a transmissão de seus valores que são, na verdade, empobrecidos frente aos das culturas locais (BANIWA, 2008, p. 69). Contudo, eles não contemplam os saberes, conhecimentos e tradições de outros grupos, como os dos indígenas, que foram construídos e constituídos muito antes de 1500. Ademais, excepcionalmente, os conhecimentos tradicionais passaram a sofrer, após essa data, um processo de destituição de sua condição sociocultural, política, econômica.

Ações que levaram à exclusão de aspectos fundamentais da vida tradicional local em benefício de valores ditos "universais". A generosidade, a solidariedade, a igualdade, os cuidados com o meio ambiente se perderam quase que totalmente (BALÉE, 1993, p. 386); todavia, ainda podem ser encontrados em sociedades tradicionais (como as ribeirinhas, as caboclas, os quilombolas, as caçadoras e coletoras ou as isoladas). Esses valores se perderam em nome da ganância do povo pela mercadoria (KOPENAWA; ALBERT, 2015).

Betha K. Becker tem a mesma reflexão que o xãma yanomami sobre a destruição dos saberes ancestrais dos povos da floresta. Ela aposta que está em curso na região amazônica a transformação de bens da natureza em mercadoria, uma ação promovida por brancos donos de grandes corporações multinacionais. Cita inúmeras empresas que já desenvolvem esses tratamentos na região e têm obtido lucros estratosféricos com a transformação - até do ar - em mercadoria: o que ela denomina de mercado do ar (BECKER, 2005, p. 77).

\section{Entendendo o outro}

Diversas músicas indígenas apontam para as necessidades pelas quais esses povos passam, como é o caso, por exemplo, daquela criada 
pelos indígenas moradores da Terra indígena Raposa Serra do Sol, em Roraima. Essas músicas contribuíram para disseminar os problemas que ocorriam ali, sendo úteis para ampliar os espaços sociais visando remediar as necessidades grupais pelas quais passavam os grupos daquela região (BANIWA, 2008, p. 71). Por meio das músicas, divulgaram suas lutas e seus motivos - como por exemplo, a demarcação de terras, uma luta muito antiga. Nesse caso, vemos que o conhecimento indígena, aliado às novas tecnologias, contribuiu na busca para salvar suas tradições e interesses. E pode ser deste modo em outros locais da região amazônica, como o Alto Solimões.

Diminuir a ignorância a respeito dos saberes tradicionais do outro é uma busca importante. Se maiores fatias da população brasileira souberem a importância sociocultural dos saberes desse outro, e se usarem esses conhecimentos e procedimentos, melhores serão as relações entre os grupos e a sociedade do entorno.

É importante que sejam lembradas e valorizadas as questões educacionais da tríplice fronteira (JUSTAMAND, 2012). Por que nessa região, outras formas de ensino são necessárias devido à diversidade linguística, sociocultural e ambiental. Muitas são tentativas híbridas visando à prática intercultural. As escolas interculturais é que teriam esse objetivo de permitir o conhecimento e o reconhecimento da existência de outras formas de ver, pensar e agir no mundo - ao menos no discurso formal oral e no escrito. Porque, em muitos casos, como assevera Gersem Baniwa, tais escolas são os túmulos da educação voltada para a diversidade (2008). De qualquer forma, se essas escolas funcionarem, como se prevê nas leis, elas servirão para "abrir" cabeças para a real diversidade cultural e sua importante contribuição para a região, Brasil e mundo.

Os grupos tradicionais, minorias étnicas, têm conhecimentos milenares significativos úteis em relação à botânica, química, matemática, geografia, biologia, antropologia, história; e estes são diferentes dos 
ensinados em escolas formais. São saberes que precisam ser reconhecidos nacionalmente, bem como serem difundidos. Warnick Kerr salienta que os grupos indígenas detêm conhecimentos acumulados durante séculos, mas não sabemos quem são os seus autores, quem os desenvolveu e para que; isso é informação incompleta (KERR, 2005, p. 65).

\section{A democracia e o outro}

Somente com abertura democrática real às "minorias" étnicas e culturais é que teremos uma outra sociedade. A real democracia é medida e avaliada de acordo com o modo como a sociedade nacional trata as suas minorias étnicas-culturais. Se estas forem tratadas com exclusão, não teremos uma sociedade democrática.

São Gabriel da Cachoeira, município do estado do Amazonas, é o único no país que possui mais de uma língua como a oficial, um exemplo para a incorporação do outro, do diferente e de suas necessidades socioculturais (BANIWA, 2008). Dessa maneira, o outro, ou melhor, os outros, se veem representados culturalmente nas escolas em que se ensinam as línguas oficiais da localidade; o conhecimento tradicional está em prática nesta cidade.

Imaginamos que seria interessante criar uma transmissora própria de televisão para as questões indígenas do país. Essa criação ajudaria na divulgação dos saberes e conhecimentos tradicionais desses grupos. E concordamos com algumas medidas já tomadas, que ajudam a pensar a nossa sociedade de modo diverso. Exemplo disso foi a ação do Ministério da Cultura que reconheceu uma cachoeira como local sagrado para os grupos indígenas da região de São Gabriel da Cachoeira - algo que poderia ser repetido em outros locais. Esse reconhecimento é um avanço sociocultural para todas as nações indígenas e para a democracia brasileira, em especial, para as crenças religiosas (BANIWA, 2008). 
Entendo que é preciso valorizar a construção cultural religiosa do outro, inclusive das crenças desse outro, que é diferente de nós. Por esse motivo, acredito que é preciso respeitar os locais sagrados desses grupos, mas também é preciso respeitar o modo de pensar e seus cultos, marcados por densidade de meditação, assim como outras religiões. Essas religiões têm seus xamãs, que influenciam os grupos e são consultados para curas. $\mathrm{O}$ contato com o "branco cristão" empobreceu a cultura desses grupos, sendo que muitos desses saberes xamânicos foram perdidos em troca de princípios cristãos, prontos e embalados, com padrões de valores e modos de vida.

\section{A vida do outro}

Para tratar das questões relativas à vida do diferente, do outro, contamos com os comentários relevantes de Claudia Tereza Signori Franco. A autora assevera que há pouco tempo, na história nacional, criouse o Projeto de Iniciativas Comunitárias Indígenas, ocorrida durante a Conferência Nacional de Saúde Indígena, em Luziânia, no ano de 2001. Lá, foram elaboradas propostas não somente para facilitar a saúde e o tratamento de doenças entre os povos indígenas, mas também para contribuir com a sua sustentabilidade. Assim, dentre as propostas estavam

1 - a busca pela redução da mortalidade infantil, por meio de realização de mútua ajuda entre os saberes tradicionais e não tradicionais indígenas;

2 - a promoção da segurança alimentar e nutricional, também mesclando saberes e conhecimentos;

3 - o respeito e valorização dos saberes e práticas tradicionais de cada etnia; 
4 - a valorização das organizações das mulheres indígenas, sem essas organizações e seus saberes acumulados ao longo de milhares de anos, todos temos muito a perder;

5 - a proteção à saúde;

6 - as preocupações com a saúde mental (FRANCO, 2010, p. 53).

Para concretizar as propostas, seguem as seguintes ações:

1 - a adequação das propostas às comunidades indígenas;

2 - as preocupações com os custos e com o tempo de aplicação de cada projeto de saúde nas comunidades indígenas;

3 - a não dependência da aprovação de outros projetos para que se realize os projetos de saúde;

4 - as propostas de saúde não podem, de forma alguma, prejudicar o meio ambiente;

5 - é preciso que se garanta claramente o envolvimento das mulheres indígenas nos processos de realização, envolvimento, funcionamento e desenvolvimento dos projetos;

6 - que todos os materiais comprados e obras realizadas serão doados e mantidos, permanecendo nas comunidades dos projetos (FRANCO, 2010, p. 54).

Essas propostas e ações são úteis para a melhoria de vida dos indígenas, muito além da saúde. Visam à incorporação dos diversos segmentos sociais dentro dos grupos, como as mulheres e sua participação nas tomadas de decisões. Visam ainda às preocupações com a alimentação e com o meio ambiente; demonstram a vontade de interação com a sociedade do entorno e com as questões essenciais da vida local, buscando o diálogo e o respeito à cultura diferente, do outro. 
A conferência demonstra preocupação com a preservação dos saberes milenares que essas sociedades detêm. Além disso, propõe que deva ser buscada a preservação ambiental, ampliando a quantidade de parques federais, estaduais e municipais (KERR, 2005, p. 68). O parentesco indígena, um modo muito típico de relação na qual a família nuclear, alargada, próxima, é incorporada nas ações dos grupos, é valorizado. Essa prática, na verdade, é um saber tradicional importante e garantidor de relações sociais plenas, mais harmoniosas e de vidas amistosas. Trata-se de um aprendizado ancestral entre os indígenas.

O parentesco é ainda propiciador de relações intensas com o meio ambiente. Relações de uso, respeito. Esse manejo da vida silvestre e a sua relação são praticados há anos pelos mais diversos grupos indígenas, nunca sendo mediados pela sua destruição. Afinal, são muitos anos lidando com esse meio ambiente e dele tirando benefícios (KOPENAWA; ALBERT, 2015).

$\mathrm{Na}$ região amazônica, há inteligência ecológica, influente e insuspeita, anterior a qualquer saber ocidentalizado. É um saber que não visa à alteração do meio, mas sim, de viver e tirar dele o que tem de melhor a oferecer; seus habitantes, há muito tempo, conhecem a fertilidade dos solos, das planícies e da constante possibilidade de pesca nos grandes rios e nos menores, como salienta Aziz Ab'Sáber (AB'SÁBER, 2005, p. 12).

Como assevera Maurício Tragtenberg, é preciso urgentemente substituir a delinquência acadêmica universitária. Essa que somente busca formar a mão de obra dócil que servirá à reprodução ampliada do capital (TRAGTENBERG, 1979, p. 9). É preciso notar que temos o que aprender com os outros, com aqueles que não estão na academia, como xamãs, pajés, mestres artesãos, dentre outros sábios tradicionais.

Torna-se importante, dessa forma, estudar essas comunidades e o que elas oferecem de saberes e conhecimentos para o mundo. Diversas etnografias demonstram que os povos da Amazônia detêm um enorme 
cabedal de conhecimentos tradicionais - estes têm sido frequentemente esquecidos ou emudecidos pela sociedade civilizada ou a de seu entorno.

Tais conhecimentos tradicionais, depositárias de acúmulos de tempos imemoriais são, sem dúvidas, úteis para a humanidade, tanto na floresta amazônica quanto nos campos e cerrados. Robert L. Carneiro indica que entre os kuikuru, as mais diversas plantas e o que se tira delas são a base para as suas produções culturais; servem para fazer casas, medicamentos, comida, transportes, perfumes, cosméticos e artefatos; usos que ocorrem por conhecerem intensamente o meio em que vivem (CARNEIRO, 1997, p. 43-4).

Os habitantes da floresta conhecem a vida dos animais e das plantas que os rodeiam. Esses grupos usam-se disso em benefício sociocultural, medicinal e político (KOPENAWA; ALBERT, 2015). É preciso fazer essa ponte da compreensão entre as distintas culturas indígenas e os seus saberes tradicionais com a cultura ocidentalizada e dominante.

Impedir a extinção desses registros tradicionais, que podem ser indígenas, quilombolas, ribeirinhos, ciganos, caboclos - e que são imemoriais - é fundamental para o futuro uso por parte de todas e todos, sem discriminação ou preconceito!

\section{Considerando finalmente: um chamamento!}

É preciso compreender, respeitar, divulgar, entender, criar junto, mover-se, para garantir que tais conhecimentos tradicionais e imemoriais nunca sejam deixados de lado, nem emudecidos, nem esquecidos! É preciso também ampliar e amplificar a luta para manter esses conhecimentos e os seus recíprocos modos de vida, bastiões exemplares para todos os seres da espécie humana! É possível viver de outra forma, sem a exploração entre os humanos, como ocorre, visivelmente, no capitalismo. 
$\mathrm{Na}$ região amazônica, de fronteiriça tríplice, do Alto Solimões, temos o privilégio de viver e conhecer de perto alguns desses saberes multiculturais, pluriétnicos e internacionais, vivenciados com utilidade sociocultural e ambiental.

Convoco todas e todos a se tornarem instrumento de luta pela defesa e salvaguarda dos conhecimentos tradicionais, que são a história local e representam cultura, harmonia ambiental e vida.

Convoco-lhes para que curemos nossas cabeças - que muitas vezes é seduzida pelas belas palavras do sistema - e lutemos pela manutenção, divulgação e maior compreensão da saberia tradicional local, que entre outras, é indígena e ancestral nas terras conhecidas atualmente como Brasil.

\section{Referências}

AB’SÁBER, Aziz. Entrevista. Aziz Ab’Sáber: problemas da Amazônia brasileira. Estudos Avançados, n. 19, (53), Dossiê Amazônia brasileira I, EdUSP, São Paulo, 2005.

ADODATO, Sérgio. Amazônia, a floresta assassinada. Falta muito pouco para matála de vez: São Paulo: Terceiro Tempo, 2006.

BALÉE, William. Biodiversidade e os índios amazônicos. In: VIVEIROS DE CASTRO, Eduardo \& CUNHA, Manuela Carneiro da (orgs.). Amazônia: etnologia e bistória indígena. São Paulo: Núcleo de História Indígena e Indigenismo da USP; FAPESP, 1993.

BANIWA, Gersem Luciano. Diversidade Cultural, Educação e a questão indígena. In: BARROS, José Márcio. Diversidade cultural: da proteção à promoção. Belo Horizonte: Autêntica, 2008.

BARÉ, Braz França. Baré-Mira Iupirungá/Origem do Povo Baré. In: HERRERO, Marina \& FERNANDEZ, Ulysses (orgs.). Baré. Povo do Rio. São Paulo: SESC, 2015. 
BARRETO, João Paulo Lima. Wai-Mabsã: peixes e bumanos. Um ensaio de Antropologia. Dissertação (mestrado). Programa de Pós-Graduação em Antropologia da UFAM. Manaus: 2013.

BECKER, Bertha K. Geopolítica da Amazônia. Estudos Avançados, n. 19, (53), Dossiê Amazônia brasileira I, EdUSP, São Paulo, 2005.

BIANCCHI, Antonio. Ayhuasca e xamanismo indígena na selva peruana: o lento caminha da conquista. In: LABATE, Beatriz Caiuby \& GOULART, Sandra Lucia (orgs.). O uso ritual das plantas de poder. Campinas: Mercado das Letras, 2005.

CARNEIRO, Robert L. O uso do solo e classificação da floresta (Kuikúro). In: Ribeiro, Berta G. (org.). Suma etnológica brasileira. Vol. I Etnobiologia. Belém: EdUFPA, 1997.

CRUZ, Tharcisio Santiago. Dimensões socioambientais e urbanas de Benjamin Constant - AM. In: JUSTAMAND, Michel \& RODRIGUES, Gilse Elisa (orgs.). Fazendo Antropologia no Alto Solimões. Embu das Artes: Alexa Cultural, 2012.

ECHEVERRI, Juan Alvaro \& PEREIRA, Edmundo. "Mambear coca não é pintar a boca de verde": notas sobre a origem e o uso ritual da coca amazônica. In: LABATE, Beatriz Caiuby \& GOULART, Sandra Lucia (orgs.). O uso ritual das plantas de poder. Campinas: Mercado das Letras, 2005.

FRANCO, Claudia Tereza Signori. Iniciativas comunitárias de promoção à saúde indígena: reflexões sobre a proposta de protagonismo indígena para projetos de desenvolvimento na área de saúde. In: SOUSA, Cássio Noronha Inglez de; ALMEIDA, Fábio Vaz Ribeiro de; LIMA, Antonio Carlos de Souza \& MATOS, Maria Helena Ortolan. Povos indígenas: projetos e desenvolvimento II. Brasília: Paralelo 15, Rio de Janeiro: Laced, 2010.

JUSTAMAND, Michel. Neoliberalismo: a máscara atual do capital. Rio de Janeiro: Achiamé, 2010.

JUSTAMAND, Michel. O Brasil desconbecido: as pinturas rupestres de São Raimundo Nonato - PI. Embu das Artes: Alexa Cultural, 2015.

JUSTAMAND, Michel. A importância da educação na fronteira. JUSTAMAND, Michel \& RODRIGUES, Gilse Elisa (orgs.). Fazendo Antropologia no Alto Solimões. Embu das Artes: Alexa Cultural, 2012. 
KERR, Warwick. Entrevista. Warnick Kerr: a Amarônia, os indios e as abelhas. Estudos Avançados, n. 19, (53), Dossiê Amazônia brasileira I, EdUSP, São Paulo, 2005.

KOPENAWA, Davi \& ALBERT, Bruce. A queda do Céu. Palavras de um xamã yanomami. Trad. Beatriz Perrone-Moisés. São Paulo: Cia das Letras, 2015.

LIMA, Widney Pereira de. Reza e cura: uma etnografia de rezadores em Benjamin Constant - Amazonas. In: JUSTAMAND, Michel \& RODRIGUES, Gilse Elisa (orgs.). Antropologia no Alto Solimões. Embu das Artes: Alexa Cultural, 2012.

LUNA, Luis Eduardo. Narrativas da Alteridade: a ayahuasca e o motivo de transformação em animal. In: LABATE, Beatriz Caiuby \& GOULART, Sandra Lucia (orgs.). O uso ritual das plantas de poder. Campinas: Mercado das Letras, 2005.

MARTINS, Cristian Farias; NASCIMENTO, Rudson Torres do \& OLIVEIRA, Maria Elenir Silva de. A imigração peruana para o Alto Solimões: relatos etnográficos da mobilidade humana numa região de fronteira. In: JUSTAMAND, Michel \& SILVA, Adailton (orgs.). Fazendo Antropologia no Alto Solimões 2. Embu das Artes: Alexa Cultural, 2015.

MOORE, Carlos. Racismo e Sociedade. Belo Horizonte: Maza Edições, 2007.

RODRIGUES, Gilse Elisa. Reflexões Antropológicas, saberes interculturais e diálogos femininos no Vale do Javari/AM. In: JUSTAMAND, Michel \& RODRIGUES, Gilse Elisa (orgs.). Fazendo Antropologia no Alto Solimões. Embu das Artes: Alexa Cultural, 2012.

SAENS, David Adan Teixeira. A construção da identidade israelita no município de Benjamin Constant/AM. In: JUSTAMAND, Michel \& RODRIGUES, Gilse Elisa (orgs.). Antropologia no Alto Solimões. Embu das Artes: Alexa Cultural, 2012.

TOBÓN, Marco. "A onça e o comércio" e o conflito armado entre Gente de centro: a memória e a defesa da vida. In: JUSTAMAND, Michel \& SILVA, Adailton (orgs.). Fazendo Antropologia no Alto Solimões 2. Embu das Artes: Alexa Cultural, 2015.

TRAGTENBERG, Maurício. A delinqüência acadêmica. O poder sem saber e o saber sem poder. São Paulo: Rumo Gráfica Editora, 1979. 